the paralysis ; and this would also afford us a further clue to the time required for its removal. Inasmuch, however, as we never can know how far the nervous structures may have been injured, our prognosis must necessarily be guarded. In Case Ir, where the paralysis was confined to a single muscle, and the history pointed to a limited apoplexy, six weeks sufficed for the restoration of function. In the case about to be narrated, the history, so far as it was obtained, led also to the inference that the cause of the paralysis was apoplectic, but more extensive and intracranial; and complete recovery did not ensue till nearly three years after the first seizure. The case is, unfortunately, very meagrely taken, but is valuable, if only for the purpose of proving that the duration of the paralysis, within certain limits, does not form a barrier to successful treatment, or forbid us holding out hopes of recovery to the patient.

CAsE v. Double Divergent Strabismus, with Partial Ptosis of both Lids, of Two Years' Duration: Cured. Caroline P., aged 43, dressmaker, fresh coloured, and not unhealthy-looking, came under my care at the Ophthalmic Hospital, Southwark, on January 7th, 1861, with the following symptoms, for which she had previously been under treatment at two hospitals for nearly twelve months. There was partial ptosis of both upper lids, and double divergent stra. bismus. In the right eye there was, in addition to paresis of the levator palpebræ muscle, a similar affection of the inferior rectus; but the other ocular muscles were not appreciably affected. The pupil acted well; and the vision and accommodation of this eye were good. In the left eye, there was complete paralysis of the internal rectus, and partial paralysis of the levator palpebræ and of the superior retus. The pupil, though of medium size, acted sluggishly. The accommodation was imperfect; the vision misty.

History. The patient stated that the paralysis had existed for about two years, without having been preceded or accompanied by any fit, pain in the head, or giddiness. She had, however, been much reduced by what she termed bleeding piles; $i$. e., there had been hæmorrhage from the rectum for three or four years before the paralytic attack, and sometimes to a considerable amount; and it was on the stoppage of this discharge that the above symptoms of paralysis appeared. Menstruation was scanty, but regular. She had no leucorrhœa, and had never had syphilis or any disease of the generative or urinary organs. She had had one child, which lived only three weeks.

Treatment. This consisted in her taking, simply as a tonic and aperient, three times a day, a drachm of solution of bichloride of mercury in an ounce of decoction of cinchona; and gr. $v$ of blue pill with colocynth, as an aperient, twice a week.

March 8th. The above medicine had been taken regularly since the 7th of January, and I had seen the patient once a week; and to-day there was observed, for the first time, some increase of power in the left rectus internus. The cornea could be moved inwards just beyond the centre.

July lst. Up to this time, there had been a very slow yet decided increase in the power of the paralysed muscles. The ptosis was less, and both globes could be more freely rotated in the direction of the paralysed muscles; but the patient complained of feeling very weak and nervous. There had been no visible mercurial effects produced. She was directed to leave off the medicine for a time; and, as a placebo, a five-grain galbanum pill was prescribed every night.

Oct. 7th. She complained of loss of appetite and debility, and there was no marked improvement in the condition of the eyes. I therefore prescribed a draught of infusion of quassia and camphor mixture, each 3 iv, three times a day. After taking this a week, she arose one morning with her eyes perfectly straight; the ptosis had disappeared, and all confusion of vision had vanished. She was discharged well on the 31st, having had no relapse. All traces of paralysis had disappeared from both eyes, and their movements were perfect and in unison.

It would be easy to multiply examples of the paralytic forms of strabismus, whether simple (i.e., depending on the loss of power of a single muscle), or complicated by the symptoms due to the implication of several, as in the case last narrated. I might also have adduced examples in which the result of treatment was less favourable than in the cases cited. On the whole, however, after looking over a large number of paralytic cases that have been either under my own treatment, or fallen under my observation in the practice of others, I think we are warranted in generally giving a favourable prognosis, and that we should not be in a hurry to resort to operative measures.

In my next communication, I purpose treating of the non-paralytic varieties of strabismus.

[To be continued.]

\section{ON THE USE OF BLOOD AS A MEDICLNE.}

By Gaetano de Pascale, M.D., Nice.

Mr only object in these few lines is to call attention to the use of blood as a curative and restorative agent; if not quite new, hitherto little employed, especially in England.

Probably one of the chief impediments to a more general use of the remedy is the preconceived aversion which most people entertain at the idea of drinking this fluid.

Dr. Desmartis of Bordeaux recommended the use of warm blood, fresh from the vessels of the newly killed animal, especially for persons affected with phthisis. The ancients, as well as our modern physicians, chemists, and microscopists, confined their researches to the investigation of the several constituents of the blood; and the results of numerous analyses have not been uniform, on account of the different processes employed.

Iron has been used from the earliest ages as a tonic; I may say, as a very martial remedy. Bat, since Berzelius and Brande discovered the peroxide of iron in the red corpuscles, it has been thought that, in all cases in which we observe the anæmic state, indicated by debility, pallor of the face, arterial murmurs, etc., there is deficiency of this peroxide; consequently, iron has been looked upon as the tonic par excellence in these diseases.

But it is easy to understand that any preparation of the laboratory, either alone or in combination, is not to be compared with the iron elaborated and mixed by Nature with other principles in the form of animal blood; for only the living organism can so combine it as to be most easily assimilated. Thus, in diseases termed anæmic, from a defect either in the quality or quantity of the blood, it will be more rational to try to supply to the system the combined constituents of blood, than either of its separate ingredients, such as iron. If we call this mineral tonic and restorative, because it is able to restore the energy of the patient by improving the condition of his blood, how excellent a tonic, how still more restorative, must be animal blood, containing, as it does, all other principles essential to nutrition. 
I admit that facts should be the base of all medical theory ; nevertheless, I propose only an outline of my experience with this remedy.

I have watched this winter, at Nice, four people affected with phthisis, who have followed the treatment for some months, one of them under my special care. In two of these four persons, the lymphatic temperament predominated, and in one the disease was so far advanced that I did not expect him to survive many days. At present, I can assert that the change in all four is very perceptible. The increased nutrition and improved health are relatively surprising. They themselves assure me that the cough, expectoration, and night-sweats have all diminished. Yet my own special patient presents, on auscultation and percussion, no appreciable amelioration.

As to the use of raw meat, as prescribed by Pro. fessor Fuster of Montpellier, I can only stay to express my approval of it; as I may also incidentally do of the chalybeates of Dr. Milliet of Tours, and the hypophosphites of $\mathrm{Dr}$. Churchill and many others.

Certainly, without flattering ourselves as to the complete and easy cure of this cruel disease, whether by means of blood, raw meat, iron, or other remedies, we may ask why, with the farther aid of a residence in a suitable climate, it may not be surmounted by the constitutional power, and at length, perhaps, disappear.

The diminution of anæmia in one of the above named patients, after four months' treatment, decided me to try drinking blood in my own case, having never completely recovered from marsh-fever, contracted during my service at the siege of Venice in 1848-49. After years of suffering, in spite of all the preparations of Peruvian bark, arsenic, iron, etc., finding myself much debilitated, with paleness of the face, and indeed the whole surface, dependent doubtless on the imperfect elaboration of the blood by the liver and spleen, principally the latter, which be. comes large and painful at each access, often precipitated by atmospheric change-I this winter commenced using blood, instead of having renewed recourse to the usual remedies.

At the end of a month, I perceived a sensible im. provement; I was less liable to profuse perspiration after slight exertion; and, with increased strength and feeling of improved health, I saw the colour of my face, as well as of the whole body, in good measure returned. But I do not consider myself cured; I do not think the liability to a relapse destroyed; still, by continuing my restorative beverage at intervals more or less prolonged, I hope to render the attacks less frequent, and in time to entirely avoid them.

As in phthisis, so in anæmia consequent on intermittent fever ; in chlorosis ; in protracted convales cence; and in many chronic diseases-the use of animal blood may be prescribed. The advice given by men of science, and the reports of cures, will cause patients to conquer their repugnance to such a drink ; and some day, perhaps, we shall see it classed among our most valuable remedies.

The blood of the calf, as more easily digested, may be first tried. After a few days, the blood of the ox or any other animals can be used, when that of these two cannot be obtained. Taken in the morning, fasting, its digestion is most easily conpleted. This time also furnishes the opportunity of exercise in the open air afterwards. The dose to commence with is four ounces, gradually increased to twelve, according to the judgment of the physician, who will regulate the duration of the treatment.

I close by repeating that, having once overcome the repugnance for this tepid drink, which, colour 464 exceptedy. is not wotse than "milk warm from tho cow", I am sure that it will be easily followed by patients, and prescribed by physicians in preference to every other restorative and curative agent.

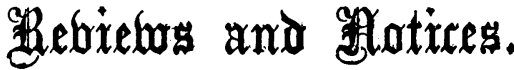

The Principles and Practice of Medical Jurisprudence. By Alfred Swaine Taylor, M.D., F.R.S., Fellow of the Royal College of Physicians, and Professor of Medical Jurisprudence and Chemistry in Guy's Hospital. Pp. 1186. London : 1865.

MEDrCAL students, and all who have a dread of that monster' a big book, must not be alarmed at the appearance of this volume of 1186 closely printed pages, nor think that Dr. TAYLOR inflicts it on them as a substitute for the very useful Manual of Medical Jurisprudence, which has during the last twenty years enjoyed merited popularity as a text-book. The Manual will continue to be published as before; but Dr. Taylor has found it necessary to alter the plan of the work, and, by a process of interstitial: deposit and enlargement, to produce the present volume; which, besides a fuller discussion of the subjects contained in the Manual, and the introduction of a number of wood-engravings, contains remarks on several matters not referred to in the smaller volume. The Manual is a sufficient and comprehensive book for students; but still the large work contains no more information than should we within the reach of all practitioners; seeing that any medical man may, almost at any moment, be called. on to aid in the elucidation of questions of a medicolegal nature.

Before commencing the consideration in detail of the numerous topics contained in the rolume, Dr. Taylor offers, in an Introduction, his opinions on several matters of general principle. The topics discussed in the introduction are the following: The Practice of Medical Jurisprudence; Medical and Medico-Legal Duties contrasted; Medical Reports Coroners' Inquests ; Inspections; Medical Wit. nesses ; Trial at the Assizes ; Subpœnas ; Examination in Chief ; Cross-examination and Re-examination; Quotations from Books; Presence of Witnesses in Court; Rules for the Delivery of Evidence; Medical Experts; Medical Counsel; and Conflicting Medical Testimony.

In his comments on Medical and Medico-Legal Duties, and on the drawing up of Medical Reports, Dr. Taylor gives some very sound advice. It is, he points out, a great error for a medical man to suppose that, because he has never been called on to give evidence in a medico-legal case, he never will be so called on ; or that, if his assistance in such a matter be required, the proper mode of dealing with it is to be acquired intuitively. A practitioner may at any time, under the influence of unforeseen and unavoidable circumstances, be required to meet all the difficulties that may occur to a skilled witness during examination in the course of a coroner's inquest, or of a civil or criminal trial. The possession of sound professional knowledge, or thorough competency as a physician or surgeon, however valuable as a groundwork, does not constitute all that is required to fit a medical man for being a witness in a 